\title{
Direct Synthesis of Highly Porous Interconnected Carbon Nanosheets and their Application as High-Performance Supercapacitors
}

Marta Sevilla* and Antonio B. Fuertes

Instituto Nacional del Carbón (CSIC), P.O. Box 73, Oviedo 33080, Spain.

*Corresponding autor: martasev@incar.csic.es

\begin{abstract}
An easy, one-step procedure is proposed for the synthesis of highly porous carbon nanosheets with an excellent performance as supercapacitor electrodes. The procedure is based on the carbonization of an organic salt, i.e. potassium citrate, at a temperature in the $750-900{ }^{\circ} \mathrm{C}$ range. In this way, carbon particles made up of interconnected carbon nanosheets with a thickness of $<80 \mathrm{~nm}$ are obtained. The porosity of the carbon nanosheets consists essentially of micropores distributed in two pore systems of $0.7-0.85 \mathrm{~nm}$ and $0.95-1.6 \mathrm{~nm}$. Importantly, the micropore sizes of both systems can be enlarged by simply increasing the carbonization temperature. Furthermore, the carbon nanosheets possess BET surface areas in the $\sim 1400-2200 \mathrm{~m}^{2} \mathrm{~g}^{-1}$ range and electronic conductivities in the range of 1.7 $7.4 \mathrm{~S} \mathrm{~cm}^{-1}$ (measured at 7.1 MPa). These materials behave as high-performance supercapacitor electrodes in organic electrolyte and exhibit an excellent power handling ability and a superb robustness over long-term cycling. Excellent results were obtained with the supercapacitor fabricated from the material synthesized at $850{ }^{\circ} \mathrm{C}$ in terms of both gravimetric and volumetric energy and power densities. This device was able to deliver $\sim 13 \mathrm{Wh} \mathrm{kg}^{-1}\left(5.2 \mathrm{Wh} \mathrm{L}^{-1}\right)$ at an extremely high power density of $78 \mathrm{~kW} \mathrm{~kg}^{-1}\left(31 \mathrm{~kW} \mathrm{~L}^{-1}\right)$ and $\sim 30 \mathrm{Wh} \mathrm{kg}^{-1}\left(12 \mathrm{Wh} \mathrm{L}^{-1}\right)$ at a power density of $13 \mathrm{~kW} \mathrm{~kg}^{-1}\left(5.2 \mathrm{~kW} \mathrm{~L}^{-1}\right)$ (voltage range of $2.7 \mathrm{~V}$ ).
\end{abstract}

Keywords: porosity, carbon, diffusion, supercapacitor, energy storage 
Porous carbons have recently attracted widespread attention in relation to their application in energy storage systems such as double-layer electrochemical capacitors (EC) and Li-ion batteries, ${ }^{1-5}$ owing to the following important properties: a) their good electronic conductivity, b) high chemical stability, c) low cost and wide availability, and d) their large surface area ascribed to pores whose size can be tuned and adapted for specific applications. These properties have made these materials the preferred choice of manufacturers for fabricating electrodes for EC systems. More specifically, porous carbons with high surface areas and a porosity made up of narrow micropores in the $\sim 0.7-1 \mathrm{~nm}$ range constitute the best option for supercapacitors because they exhibit the largest specific capacitance values (up to $\sim 14 \mu \mathrm{F} \mathrm{cm}{ }^{-2}$ in organic electrolyte). ${ }^{6}$ Usually these microporous carbons are fabricated in the form of granular powders made up of particles $>10 \mu \mathrm{m}$, which results in relatively large diffusion paths $(>5 \mu \mathrm{m})$. This is a serious drawback as it severely limits the ion-transport kinetics within the pores, resulting in a dramatic reduction in EC performance at high current densities (high power). ${ }^{7}$ In order to overcome this problem, it is crucial to reduce the effective diffusion paths. Two strategies have been adopted for this purpose. Wang et al. described the fabrication of carbon powders with a hierarchical porous structure that combines macropores, mesopores and micropores. ${ }^{8}$ The macropores act as ion-buffering reservoirs, the mesopores serve as channels for the rapid transport of ions, while the micropores are the locations for the charge accommodation in the double electrical layer. Thus, relatively large carbon particles are able to offer short effective diffusion paths, thereby improving EC performance. An alternative synthesis strategy is based on the fabrication of $3 D, 2 D$ or $1 D$ nanometer-sized 
porous carbon particles $(<200 \mathrm{~nm})$ that provide short diffusion paths $(<100 \mathrm{~nm})$. Several multi-step procedures have been reported for the fabrication of 3D porous carbon nanoparticles, but they all require expensive reagents and production on a large scale is therefore complicated. ${ }^{9-11}$ Similarly, procedures for the production of highly porous carbon nanofibers (1D) have also turned out to be complicated and only a small number of reports about them have recently appeared. ${ }^{12-14} 2 \mathrm{D}$ porous carbon nanostructures constitute a better alternative because they are easier to prepare and their thinness entails short diffusion distances. Graphene is a good example of a 2D carbon nanostructure. However, it has been observed that graphene nanosheets tend to aggregate (self-restacking) during the preparation of the electrode, which results in a substantial loss of active surface area and a reduction in electrochemical performance. ${ }^{15}$ To overcome this problem, the intercalation of several types of carbon particles (i.e. porous microspheres, nanotubes, carbon black, etc) in between the graphene sheets has been investigated. ${ }^{16-19}$ However, this additional step introduces a certain amount of complexity into the synthesis process. An alternative strategy to avoid restacking face-to-face when packed into an electrode is based on the synthesis of curved/ crumpled graphene sheets ${ }^{20-22}$ or folding graphene. ${ }^{23,24}$ Such morphology increases the effective surface area providing significantly improved supercapacitor performance, although the values of specific surface area achieved are still lower than $1000 \mathrm{~m}^{2} \mathrm{~g}^{-1}$.

In relation to these problems, the preparation of non-aggregated highly porous amorphous carbon nanosheets has generated increasing interest. ${ }^{25,}{ }^{26}$ Fan 
et al. reported the fabrication of mesoporous carbon nanosheets with a unique pillared architecture that avoids the restacking of the carbon sheets and thereby improves EC performance. ${ }^{27}$ The synthesis procedure requires several steps and the use of previously synthesized $\mathrm{MgO}$ planar nanoparticles as template. In addition, such prepared carbon particles have a relatively low surface area $(<900$ $\mathrm{m}^{2} / \mathrm{g}$ ) and a porosity made up of mesopores $(\sim 7 \mathrm{~nm})$ instead of micropores, the latter being more appropriate for application in electrochemical capacitors. More recently, Wang et al. showed that highly porous interconnected carbon nanosheets obtained in a two-step procedure that involves the hydrothermal carbonization of vegetal fibers (i. e. hemp bast) followed by chemical activation with $\mathrm{KOH}$, exhibit a very good performance as EC electrodes. ${ }^{28}$ However, all these processes are somewhat complex and require several steps. For these reasons, the development of facile synthesis procedures for producing non-aggregated highly porous carbon nanosheets is still a challenge to be overcome.

In this paper, we present a template-free one-step procedure for the fabrication of non-aggregated high-surface area porous carbon nanosheets (PCNS). The PCNS are interconnected forming a desert rose-like structure that impedes these flat carbon nanoparticles from aggregating and therefore improves the ion diffusion rates. We envisage that a carbon material with these properties will exhibit a good performance as EC electrodes. The procedure for fabricating the PCNS involves the carbonization of potassium citrate by means of a synthesis strategy recently developed in our laboratory. ${ }^{29}$ The synthesis method is illustrated 
in Scheme 1. It is worth noting that these carbon materials can be easily produced in only one-step by using as precursor a widely available cheap substance.

\section{Results and Discussion}

\section{Formation and structural characteristics of porous carbon nanosheets}

The heat-treatment of potassium citrate under an inert atmosphere directly leads to the formation of desert rose-like particles composed of interconnected carbon nanosheets with a certain amount of inorganic impurities (i. e. potassium compounds). These impurities can be easily removed by washing with diluted hydrochloric acid. The potassium compounds generated during heat-treatment have a crucial role in the development of the microporous network. First, potassium carbonate is formed $\left(<650^{\circ} \mathrm{C}\right)$ and then decomposed at higher temperatures $\left(\mathrm{K}_{2} \mathrm{CO}_{3} \rightarrow \mathrm{CO}_{2}+\mathrm{K}_{2} \mathrm{O}\right)$. The $\mathrm{CO}_{2}$ thus produced reacts with carbon $\left(\mathrm{CO}_{2}+\mathrm{C} \rightarrow\right.$ $2 \mathrm{CO})$ to generate microporosity. At the same time, metallic potassium is produced via the reduction of $\mathrm{K}_{2} \mathrm{O}$ by carbon $\left(\mathrm{K}_{2} \mathrm{O}+\mathrm{C} \rightarrow 2 \mathrm{~K}+\mathrm{CO}\right)$. This potassium plays a crucial role in the generation of additional porosity because its vapours are intercalated between the graphene layers, causing the swelling and disruption of the carbon microstructure. ${ }^{30}$ The pyrolysis and gasification processes that occur during the heat treatment of potassium citrate can be monitored by means of thermogravimetric analysis. The TGA curve in Figure S1 (Supporting Information) clearly shows two weight loss steps in the temperature ranges of $200-500^{\circ} \mathrm{C}$ and $700-900^{\circ} \mathrm{C}$, which can be ascribed to the decomposition of the organic moiety and the gasification process respectively. The washing step removes completely the inorganic impurities as confirmed by the XPS general spectra depicted in Figure S2 
for the samples CK-850 and CK-900, which show that the carbon particles do not contain any inorganic impurity and they are mainly compose of carbon (> 93 at.\%), with less than 6.5 at.\% oxygen. The above results demonstrate that the use of potassium citrate as carbon precursor allows the integration of the carbonization and activation processes in only one step, simplifying the production of porous carbons considerably.

The microstructure and morphology of the carbon samples were examined by scanning electron microscopy (SEM). Figure 1a shows that the architecture of the carbon samples resembles that of a desert rose (see inset in Figure 1a). Indeed, these particles are an assembly of fully interconnected carbon nanosheets (see Figure S3) of extreme thinness as suggested by the high-magnification SEM image in Figure 1b (inset). The thickness of the carbon nanosheets was determined by means of electron energy loss spectroscopy (EELS) applied to numerous particles (Figure S4). The calculated values are in the $30-80 \mathrm{~nm}$ range for the CK-850 sample. Furthermore, the transmission electron microscopy (TEM) image in Figure 1c confirms that the carbon samples derived from the carbonization of potassium citrate are made up of highly porous particles with a $2 \mathrm{D}$ morphology. The HRTEM microphotograph shown in Figure 2d, which was taken on the edge of a CK-850 nanosheet, clearly reveals that the porosity is made up of randomly oriented narrow micropores, thereby anticipating the results obtained from the nitrogen physisorption measurements (vide infra). Additional HRTEM images of the samples CK-800 and CK-900 are provided in Figure S5. The FFT patterns included in Figure 1d and Figure S5 evidence the amorphous structure of 
the carbon nanosheets. This is corroborated by the XRD patterns and Raman spectra displayed in Figure 2, which are typical of carbonaceous materials with an amorphous-like structure. Thus, broad and low-intensity (002) and (100) bands can be identified in the XRD patterns in Figure 2a, and broad and overlapping D (1351 $\left.\mathrm{cm}^{-1}\right)$ and $\mathrm{G}\left(1587 \mathrm{~cm}^{-1}\right)$ bands are registered in the first order Raman spectra in Figure $2 \mathrm{~b}$. The deconvolution of these two overlapping bands gives rise to two additional peaks commonly identified in poorly organized carbons: i) $1135 \mathrm{~cm}^{-1}$, assigned to disordered graphitic lattice (A1g symmetry) ${ }^{31}$ or $\mathrm{sp}^{3}$-rich phase, ${ }^{32}$ and ii) $1486 \mathrm{~cm}^{-1}$, ascribed to amorphous $\mathrm{sp}^{2}$-bonded forms of carbon. ${ }^{33,34}$ It is worth noting that a slight increase of ordering is registered with the increase of the carbonization temperature. Thus, the $I_{D} / I_{G}$ ratio decreases from 0.905 for $\mathrm{CK}-750$ to 0.834 for CK-900.

Nitrogen physisorption measurements were carried out at $-196{ }^{\circ} \mathrm{C}$ to analyze the textural characteristics of the carbon nanosheets obtained by the carbonization of potassium citrate at several temperatures: $750^{\circ} \mathrm{C}, 800^{\circ} \mathrm{C}, 850^{\circ} \mathrm{C}$ and $900{ }^{\circ} \mathrm{C}$. The $\mathrm{N}_{2}$ sorption isotherms and the pore size distributions (PSDs) deduced by means of the QSDFT method are shown in Figures $3 a$ and $3 b$ respectively. The isotherm profiles displayed in Figure 3 a can be categorized as being of type I, indicating that the porosity is mainly made up of micropores. More interestingly, as the temperature of carbonization increases from $750{ }^{\circ} \mathrm{C}$ to $900{ }^{\circ} \mathrm{C}$, a widening of the knee of the isotherms takes place, which suggests an enlargement of the micropore size as the temperature increases. This is confirmed by the pore size distributions in Figure 3b, which clearly show a shift in the PSD towards larger pore 
sizes as the carbonization temperature increases. Interestingly, the PSDs reveal the presence of two pore systems in the micropore range. The main maximum shifts from 0.7 to $0.85 \mathrm{~nm}$ as the carbonization temperature increases from 750 to $90{ }^{\circ} \mathrm{C}$, whereas the second pore system is enlarged from $0.95 \mathrm{~nm}\left(750^{\circ} \mathrm{C}\right)$ to 1.6 $\mathrm{nm}\left(900^{\circ} \mathrm{C}\right)$. Moreover, it can be seen that, whereas the sample prepared at 750 ${ }^{\circ} \mathrm{C}$ is exclusively microporous, the samples prepared at $\mathrm{T} \geq 800{ }^{\circ} \mathrm{C}$ exhibit pores of up to $4-5 \mathrm{~nm}$. The textural parameters of the synthesized carbons are presented in Table 1. These results show that the carbon nanosheets exhibit high BrunauerEmmett-Teller (BET) surface areas and large pore volumes. The pore volume increases steadily with temperature from $0.59 \mathrm{~cm}^{3} \mathrm{~g}^{-1}\left(750{ }^{\circ} \mathrm{C}\right)$ to $1.30 \mathrm{~cm}^{3} \mathrm{~g}^{-1}(900$ ${ }^{\circ} \mathrm{C}$ ), whereas the BET surface area increases from $1360 \mathrm{~m}^{2} \mathrm{~g}^{-1}$ at $750{ }^{\circ} \mathrm{C}$ to 2220 $\mathrm{m}^{2} \mathrm{~g}^{-1}$ at $850{ }^{\circ} \mathrm{C}$ and then slightly decreases to $2130 \mathrm{~m}^{2} \mathrm{~g}^{-1}$ at $900{ }^{\circ} \mathrm{C}$. Moreover, analysis of the porosity by means of the D-R method confirms that these samples are essentially microporous, the micropore volume constituting more than $80 \%$ of the total pore volume (see Table 1), except for the sample synthesized at $900{ }^{\circ} \mathrm{C}$, whose micropore volume accounts for $\sim 60 \%$ of the total pore volume.

The electronic conductivity of the powder samples was measured using a four-probed method. The home-made apparatus employed for such measurements allowed the simultaneous determination of conductivity and packing density. These PCNS exhibit electronic conductivities in the range of $1.7-7.4 \mathrm{~S} \mathrm{~cm}^{-1}$ (load pressure: 7.1 $\mathrm{MPa}$ ), the conductivity being enhanced with the increase of the synthesis temperature. Especially remarkable is the conductivity of CK-900 (i.e. 7.4 $\mathrm{S} \mathrm{cm}^{-1}$ ), which is close or superior to that of materials normally used as conductive 
additives for the preparation of supercapacitor electrodes, such as Super P (8.6 S $\mathrm{cm}^{-1}$ ) or Super $\mathrm{C} 65\left(5.2 \mathrm{~S} \mathrm{~cm}^{-1}\right)$. It is, as well, higher than that of commercial activated carbons used in supercapacitors, such as Supra 50 , which possesses a conductivity of $4.3 \mathrm{~S} \mathrm{~cm}^{-1}$. With regards to the packing density, as is usual for many nanomaterials, ${ }^{35}$ they possess relatively low packing densities, decreasing from $0.50 \mathrm{~g} \mathrm{~cm}^{-3}$ at $750{ }^{\circ} \mathrm{C}$ to $0.27 \mathrm{~g} \mathrm{~cm}^{-3}$ at $900^{\circ} \mathrm{C}$ (load pressure: $7.1 \mathrm{MPa}$ ).

\section{Electrochemical performance}

The carbon nanosheets presented here have a unique structure that combines an extreme thinness (diffusion paths $<40 \mathrm{~nm}$ ) and a very large surface area (up to $\sim 2200 \mathrm{~m}^{2} \mathrm{~g}^{-1}$ ) which can be ascribed to micropores and small mesopores. Besides, they exhibit good electronic conductivity. They present therefore the appropriate characteristics for advanced electrochemical capacitors. To confirm this, the electrochemical properties of PCNS were measured in organic electrolyte, i.e. $1 \mathrm{M} \mathrm{TEABF}_{4} / \mathrm{AN}$, using a two-electrode cell system. The cyclic voltammetry curves are depicted in Figure 5 and Figure S6a and S6b. From these figures it can be seen that even at a high scan rate of $200 \mathrm{mV} \mathrm{s}^{-1}$, the curves retain a perfect rectangular shape, which indicates pure EDLC behavior and the rapid formation of the double-layer even at high rates. Specific capacitances (for a single electrode) of $\sim 120-150 \mathrm{~F} \mathrm{~g}^{-1}$ are achieved at $1 \mathrm{mV} \mathrm{s}^{-1}$ and of $\sim 80-120 \mathrm{~F} \mathrm{~g}^{-1}$ at $200 \mathrm{mV} \mathrm{s}^{-1}$ (see Figure S6c in SI). As would be expected taking into account the similarity of the electronic conductivity of CK-900 and the conductive additive Super $\mathrm{P}$ used in the preparation of the electrodes, the behavior of the supercapacitors prepared with and without the conductive additive is analogous 
(see Figures S6a and S6b). The surface area normalized capacitance values (based on the BET surface area) at low sweep rates are 8.8, 6.8, 6.6 and $6.1 \mu \mathrm{F}$ $\mathrm{cm}^{-2}$ for CK-750, CK-800, CK-850 and CK-900 respectively. These values are much higher than those determined for the activated carbon Supra $\left(\sim 5 \mu \mathrm{F} \mathrm{cm}^{-2}\right)$ and are comparable or superior to those achieved with advanced activated carbons. $^{36-40}$ This result suggests a good match between the pore size and electrolyte ions size. On the other hand, it can be observed that even at a scan rate as high as $200 \mathrm{mV} \mathrm{s}^{-1}$, capacitance fading is as low as $14-32 \%$ (see Figure S6d in SI). Especially remarkable is the behavior of the CK-850 and CK-900 samples, which retain $55-61 \%$ of their specific capacitance at the very large scan rate of 1 V/s (Figure 4c and Figure S6). Indeed, capacitance retention is better in the case of the samples synthesized at higher temperatures owing to the higher electronic conductivity and also probably to the existence of two micropore systems (see PSD in Fig. 3b) in which the larger micropores facilitate the transport of ions to the narrower micropores. Electrochemical impedance spectroscopy measurements further confirm the favorable performance of the carbon nanosheets prepared at higher temperatures. This can be deduced from an analysis of the frequency response of the normalized capacitance $\left(\mathrm{C}_{\mathrm{EIS}} / \mathrm{C}_{\mathrm{EIS}, 1 \mathrm{mHz}}\right)$ for the SCNS samples (Figure 4d). Thus, it can be seen that the relaxation time constant, $\tau_{0}$ (the minimum time needed for all the energy to be discharged from the supercapacitor cell with an efficiency $>50 \%)$ decreases from $4.4 \mathrm{~s}(\mathrm{CK}-750)$ to $1.9 \mathrm{~s}$ (CK-900). Importantly, these values are considerably lower than those measured for microporous carbons with a granular morphology, such as the commercial activated carbon Supra (8.5 s, 
see Fig. 4d), advanced activated carbons ${ }^{37}$ and carbide-derived carbons (CDCs) in organic electrolyte. $6,41,42$ These results clearly evidence the advantages of microporous carbon nanosheets over granular carbons.

In order to assess the energy and power characteristics of PCNS-based supercapacitors, galvanostatic charge/discharge cycling experiments were performed at current densities of up to $40 \mathrm{~A} \mathrm{~g}^{-1}$ for CK-750 and CK-800, and of up to $150 \mathrm{~A} \mathrm{~g} \mathrm{~g}^{-1}$ for $\mathrm{CK}-850$ and $\mathrm{CK}-900$. Examples of the charge-discharge voltage profiles at different current densities are shown in Figure S7 (Supporting Information) for the CK-800 and CK-850-based supercapacitors. At every current density, the voltage profiles are highly linear and symmetrical indicating ideal EDLC behavior, in agreement with the results obtained by cyclic voltammetry (see Figs. $4 a, 4 b$ and $4 c$ and S5a). Interestingly, a small IR drop (almost negligible for CK-850 and CK-900) is observed even at a high discharge current density of $5 \mathrm{~A} \mathrm{~g}^{-1}$ (see Figure 5a), which suggests that these materials exhibit an excellent rate performance. This is confirmed by the results in Figure $5 b$ which show the variation in specific capacitance with the current density. It can be seen that the samples synthesized at higher temperatures (i.e. CK-800, CK-850 and CK-900) have high specific capacitances (e.g. 121-134 $\mathrm{F} \mathrm{g}^{-1}$ at $5 \mathrm{~A} \mathrm{~g}^{-1}$ ) and, more importantly, excellent capacitance retention values, which at a current density of 40 $\mathrm{A} \mathrm{g}^{-1}$ are around $90 \%$. These capacitance retention values are far superior to those of microporous carbons ${ }^{37,43-45}$ and remarkable even when compared to those of mesoporous materials ${ }^{46,47}$ and carbon/graphene nanosheets. ${ }^{38,48-51}$ What is more, in the case of the CK-800, CK-850 and CK-900 samples, the specific 
capacitance remains almost constant in the $1-40 \mathrm{~A} \mathrm{~g}^{-1}$ range $(<5 \%$ of capacitance loss). This contrasts with the behavior observed for granular activated carbons commonly used in commercial supercapacitors (e.g. Supra and YP-17D), which experience a remarkable drop in specific capacitance with the increase in current density (see Figure 5b). An exceptionally good rate performance is provided by the CK-850 and CK-900 samples, which at the extremely high current density of $150 \mathrm{~A} \mathrm{~g}^{-1}$ still retain a specific capacitance of 120 and $107 \mathrm{~F} \mathrm{~g}^{-1}$ respectively (their specific capacitance fades by only $15-18 \%$ ). This behavior can be attributed to the unique structural properties of the CK-850 and CK-900 samples, which combine a thin morphology (short ion diffusion paths), a bimodal microporosity with interconnected narrow and wide micropores that improve the ion diffusion rates (vide supra), and a very good electronic conductivity (3.7 and $7.4 \mathrm{~S}$ $\mathrm{cm}^{-1}$ at 7.1 MPa respectively) which provides high electron transport rates.

The Ragone plot in Figure 5c compares the PCNS samples and the activated carbon Supra. The PCNS-based supercapacitors exhibit specific energies of $13 \mathrm{Wh} \mathrm{kg}^{-1}$ (CK-750), $16 \mathrm{Wh} \mathrm{kg}^{-1}$ (CK-800 and CK-900) and $18 \mathrm{Wh} \mathrm{kg}^{-1}$ (CK-850) at a specific power of $2.5 \mathrm{~kW} \mathrm{~kg}^{-1}$, which contrasts with the low specific energy for activated carbon Supra $\left(9 \mathrm{Wh} \mathrm{kg}^{-1}\right)$. More importantly, the specific energies of the PCNS samples are still in the $8-15 \mathrm{Wh} \mathrm{kg}^{-1}$ range at a high specific power of $10 \mathrm{~kW} \mathrm{~kg}^{-1}$, indicating that ultra-fast ion and electron transport is taking place. This is particularly relevant in the case of the CK-850 and CK-900 samples which still possess a specific energy of $12 \mathrm{Wh} \mathrm{kg}^{-1}$ at $17 \mathrm{~kW} \mathrm{~kg}^{-1}$ and 19 $\mathrm{kW} \mathrm{kg}^{-1}$ respectively, indicating that these samples can deliver a large amount of 
energy very quickly (2.5 and $2.3 \mathrm{~s}$ respectively). Figure S8 compares the Ragone plot of the PCNS with that of Supra carbon in volumetric units. The PCNS synthesized at $\mathrm{T} \leq 850{ }^{\circ} \mathrm{C}$ store similar energy per unit volume $\left(8-9 \mathrm{Wh} \mathrm{L}^{-1}\right)$ to Supra carbon (9.6 Wh L $\left.\mathrm{W}^{-1}\right)$ at low discharge rates and surpass it for high discharge rates (drain time < $10 \mathrm{~s}$ ). However, the volumetric energy-power characteristics of the sample synthesized at the highest temperature (i.e. $900^{\circ} \mathrm{C}$ ) are inferior owing to its low packing density $\left(0.27 \mathrm{~g} \mathrm{~cm}^{-3}\right.$ at $\left.7.1 \mathrm{MPa}\right)$. Thereby, taking into account both the gravimetric and volumetric energy-power characteristics, the best performing sample is CK-850.

The stability of the CK-850- and CK-900-based supercapacitors was evaluated by long-term charge-discharge cycling at several current densities (Figure $5 \mathrm{~d}$ ). It can be seen that after 10000 cycles at $10 \mathrm{~A} \mathrm{~g}^{-1}$, the system still retains $90-94 \%$ of its initial capacitance (with no increase in the equivalent series resistance, ESR), evidencing the superb robustness of the materials, even at high discharge rates. The CK-750 and CK-800 samples exhibit similar cycling stabilities, as shown in Figure S9.

Enlargement of the voltage window up to $2.7 \mathrm{~V}$ was tested in the supercapacitors after long-term cycling at $2 \mathrm{~V}$. The cyclic voltammograms recorded at $20 \mathrm{mV} \mathrm{s}^{-1}$ (Figure S10a in Supporting Information) showed no change in either the cathodic or anodic currents when the voltage window was enlarged, suggesting that the supercapacitors were stable over this voltage range. This was further confirmed by long-term cycling (5000 cycles) at $10 \mathrm{~A} \mathrm{~g}^{-1}$, after which only an 8-10 $\%$ reduction in specific capacitance was observed (Figure S10b in Supporting 
Information). In this way, by using a voltage window of $2.7 \mathrm{~V}$, it is possible to almost double the amount of energy stored in these devices. Thus, a specific energy of around $26-34 \mathrm{Wh} \mathrm{kg}^{-1}$ (depending on the type of PCNS) can be achieved without compromising either the stability (Figure S10b in Supporting Information) or power performance (Figure 5c). As the carbon weight represents $\sim 30 \%$ of the total mass of a packaged commercial EC, ${ }^{35}$ a specific energy of $\sim 8-$ $11 \mathrm{Wh} \mathrm{kg}^{-1}$ is expected for a real packaged device, which is higher than that of commercial AC-based supercapacitors. Furthermore, these PCNS-based supercapacitors are able to deliver $14-30 \mathrm{Wh} \mathrm{kg}^{-1}$ at a power density of $13 \mathrm{~kW} \mathrm{~kg}^{-}$ 1. Of particular interest are the results obtained with the CK-850- and CK-900based supercapacitors which can still deliver respectively $\sim 13 \mathrm{Wh} \mathrm{kg}^{-1}\left(5.2 \mathrm{Wh} \mathrm{L}^{-1}\right)$ at a power density of $78 \mathrm{~kW} \mathrm{~kg}^{-1}\left(31 \mathrm{~kW} \mathrm{~L}^{-1}\right)$ and $\sim 14 \mathrm{Wh} \mathrm{kg}^{-1}\left(3.8 \mathrm{Wh} \mathrm{L}^{-1}\right)$ at a power density of $112 \mathrm{~kW} \mathrm{~kg}^{-1}\left(30 \mathrm{~kW} \mathrm{~L}^{-1}\right)$. Figure 6 provides a comparison of the power and energy characteristics of the CK-850- and CK-900-based supercapacitors with those of the most advanced porous carbon materials that can be found in the literature, ${ }^{8,40,50,52,53}$ confirming its high performance, especially in terms of power handling (> $\left.20 \mathrm{~kW} \mathrm{~kg}^{-1}\right)$.

\section{Conclusions}

In summary, we have reported a novel and simple approach to produce 3D interconnected microporous carbon nanosheets. These carbon particles are produced by the direct carbonization of potassium citrate at temperatures in the $750-900{ }^{\circ} \mathrm{C}$ range. In this way, the pyrolysis of the organic moiety and the activation of the carbonaceous material can be integrated in only one step. The 
interconnected carbon nanosheets have a thickness of $<80 \mathrm{~nm}$ and, in addition, they possess large specific surface areas (up to $\sim 2200 \mathrm{~m}^{2} \mathrm{~g}^{-1}$ ) and a porosity made up of two micropore systems in the size ranges of $0.7-0.85 \mathrm{~nm}$ and $0.95-1.6 \mathrm{~nm}$. Furthermore, they exhibit good electronic conductivities, up to $7.4 \mathrm{~S} \mathrm{~cm}^{-1}$ (load pressure: 7.1 MPa). These unique structural properties allow short diffusion paths and consequently the rapid transport of ions throughout the carbonaceous matrix, as well as rapid electron transport, resulting in an excellent electrochemical performance. In particular, the samples fabricated at 850 and $900{ }^{\circ} \mathrm{C}$ display a high specific capacitance at high discharge rates, an outstanding rate capability and an excellent cycling stability in the $1 \mathrm{M} \mathrm{TEABF}_{4} / \mathrm{AN}$ organic system. At a very high specific power of $25-27 \mathrm{~kW} \mathrm{~kg}^{-1}$, their specific energy reaches $25 \mathrm{Wh} \mathrm{kg}^{-1}$. These promising results reveal the development of a one-step, facile, cost-effective and scalable synthesis strategy for the production of carbon materials that are highly suitable for the fabrication of top-performance supercapacitors. 


\section{Experimental Section}

\section{Synthesis of Materials}

In a typical synthesis procedure, $5 \mathrm{~g}$ of potassium citrate (Aldrich) was heat-treated in a stainless steel reactor under nitrogen up to desired temperature (i.e. $750{ }^{\circ} \mathrm{C}$, $800{ }^{\circ} \mathrm{C}, 850{ }^{\circ} \mathrm{C}$ or $900{ }^{\circ} \mathrm{C}$ ) at a heating rate of $3{ }^{\circ} \mathrm{C} / \mathrm{min}$ and held at this temperature for 1 hour. The black solid residue was then washed with $\mathrm{HCl}(10 \%)$. Finally, the solid was collected by filtration, washed with abundant distilled water and dried at $120^{\circ} \mathrm{C}$ for several hours. The carbon samples were denoted as $C K-X$, where $X$ is the reaction temperature (in ${ }^{\circ} \mathrm{C}$ ).

\section{Physical characterization}

Scanning electron microscopy (SEM) images were obtained on a Quanta FEG650 (FEI) instrument, whereas transmission electron microscopy (TEM) images were recorded on a JEOL (JEM 2100-F) apparatus operating at $200 \mathrm{kV}$. The nitrogen sorption isotherms of the carbon samples were measured at $-196{ }^{\circ} \mathrm{C}$ using a Micromeritics ASAP 2020 sorptometer. The apparent surface area was calculated using the BET method. An appropriate relative pressure range was selected to ensure that a positive line intersect of multipoint BET fitting $(C>0)$ would be obtained and $V_{\text {ads }}\left(1-p / p_{o}\right)$ would increase with $p / p o .{ }^{54}$ The total pore volume was determined from the amount of nitrogen adsorbed at a relative pressure $\left(P / P_{0}\right)$ of 0.95, whereas the micropore volume was determined using the DubininRadushkevich equation. ${ }^{55}$ The average pore width, $L_{0}$, was calculated by applying the equation proposed by Stoeckli and Ballerini. ${ }^{56}$ The pore size distributions (PSD) were determined by means of the Quench Solid State Density Functional 
Theory (QSDFT) method for nitrogen. ${ }^{57,}{ }^{58}$ X-ray diffraction (XRD) patterns were obtained on a Siemens D5000 instrument operating at $40 \mathrm{kV}$ and $20 \mathrm{~mA}$, using CuK $\alpha$ radiation. The Raman spectra were recorded on a Horiva (LabRam HR-800) spectrometer. The source of radiation was a laser operating at a wavelength of 514 $\mathrm{nm}$ and at a power of $25 \mathrm{~mW}$. X-ray photoelectron spectroscopy (XPS) was carried out on a Specs spectrometer, using $\mathrm{Mg} \mathrm{Ka} \mathrm{(1253.6} \mathrm{eV)} \mathrm{radiation} \mathrm{from} \mathrm{a} \mathrm{double}$ anode at $150 \mathrm{~W}$. Thermogravimetric analysis (TGA) curves were recorded on a TA Instruments Q600 TGA system.

The dc electrical conductivity of the carbon powders was determined in a home-made apparatus (four-probe method) by pressing the powders between two plungers, into a hollow Nylon cylinder (inner diameter of $8 \mathrm{~mm}$ ), and applying a pressure of $7.1 \mathrm{MPa}$.

\section{Electrochemical characterization}

Electrodes were prepared by mixing $85 \mathrm{wt} \%$ of active material with $10 \mathrm{wt} \%$ of polytetrafluoroethylene (PTFE) binder (Aldrich, $60 \mathrm{wt} \%$ suspension in water) and 5\% Super P (Timcal). For CK-900, electrodes were also prepared without conductive additive by mixing $90 \mathrm{wt} \%$ of active material and $10 \mathrm{wt} \%$ of PTFE. The electrochemical measurements were performed in two-electrode Swagelok ${ }^{\mathrm{TM}}$ type cells using stainless steel current collectors. Electrochemical capacitors were built using two carbon electrodes of comparable mass, electrically isolated by glassy fibrous separator. A $1 \mathrm{M}$ tetraethylammonium tetrafluoroborate salt $\left(\mathrm{TEABF}_{4}\right.$, electrochemical grade, Sigma-Aldrich) solution in acetonitrile (AN, 99.8\%, anhydrous, Sigma-Aldrich) was used as electrolyte. The electrochemical 
characterization was performed using a computer-controlled potentiostat (Biologic VMP3 multichannel generator). Commercial activated carbon commonly used in commercial supercapacitors (Supra DLC-50, Norit, $\mathrm{S}_{\mathrm{BET}}=1890 \mathrm{~m}^{2} \mathrm{~g}^{-1}$, average pore width $\sim 1.3 \mathrm{~nm}$ ) was analyzed for comparison.

Cyclic voltammetry was conducted between 0 and $2-2.7 \mathrm{~V}$ at increasing sweep rates from 1 to $1000 \mathrm{mV} \cdot \mathrm{s}^{-1}$. The specific gravimetric capacitance of a single electrode was calculated from the area of the voltammograms by means of the following formula:

$$
\mathrm{C}_{\mathrm{sp}}=\frac{\int \mathrm{IdV}}{v \cdot \mathrm{m} \cdot \Delta \mathrm{V}}
$$

where $I=$ current $(\mathrm{A}), v=$ scan rate $(\mathrm{V} / \mathrm{s}), \Delta V=$ voltage window $(\mathrm{V})$, and $m=$ mass (grams) of carbon material in the working electrode.

Galvanostactic charge/discharge cycling was also performed in the 0 to $2-2.7 \mathrm{~V}$ range at current densities in the $0.05-150 \mathrm{~A} \mathrm{~g}^{-1}$ range, based on the active mass of a single electrode. The specific gravimetric capacitance of a single electrode determined from the galvanostatic cycles was calculated by means of the formula:

$$
\mathrm{C}_{\mathrm{sp}}=\frac{2 \cdot \mathrm{I}}{(\mathrm{dV} / \mathrm{dt}) \cdot \mathrm{m}}
$$

where $d V / d t=$ the slope of the discharge curve $\left(\mathrm{V} \mathrm{s}^{-1}\right)$.

Electrochemical impedance spectroscopy (EIS) was performed at open circuit voltage (i.e. $0 \mathrm{~V}$ ) within the frequency range of $1 \mathrm{mHz}$ to $100 \mathrm{kHz}$ and a $10 \mathrm{mV} \mathrm{AC}$ amplitude. Plots of the dependence of the capacitance on frequency were recorded 
to characterize the impedance of the tested samples. The specific gravimetric capacitance of a single electrode, $\mathrm{C}_{\mathrm{EIS}}(\mathrm{F} / \mathrm{g})$, was calculated according to the following formula and normalized with respect to the specific gravimetric capacitance at $1 \mathrm{mHz}$ :

$$
C_{E I S}=\frac{2 \cdot \mid \operatorname{Im}(\mathrm{Z})}{2 \pi \mathrm{f} \cdot\left[(\operatorname{Im}(\mathrm{Z}))^{2}+(\operatorname{Re}(\mathrm{Z}))^{2}\right] \cdot \mathrm{m}}
$$

where $f$ is the operating frequency $(\mathrm{Hz})$, and $\operatorname{Im}(Z)$ and $\operatorname{Re}(Z)$ are the imaginary and real components of the total device resistance $(\mathrm{Ohm})$. The relaxation time constant, $\tau_{0}$, which separates the capacitive behavior and the resistive behavior of the supercapacitor, was deduced from the frequency $f_{0}$ as follows: $\tau_{0}=1 / f_{0}$, where $f_{0}$ can be obtained from the real capacitance plot at $C^{\prime}=C_{1 \mathrm{mHz}} / 2$ and from the imaginary capacitance plot where it corresponds to the peak frequency.

To trace the Ragone plots, the specific energy $\left(\mathrm{Wh} \mathrm{kg}^{-1}\right)$ was calculated using the following formula:

$$
\mathrm{E}=\frac{1}{2} \mathrm{C}_{\text {cell }} \Delta \mathrm{V}_{\mathrm{d}}^{2}
$$

where $C_{c e l l}$ is the specific capacitance of the total cell $\left(\mathrm{F} \mathrm{g}^{-1}\right)$ and $\Delta V_{d}$ is the operation voltage $\left(\mathrm{V}_{\max }-\mathrm{IR}\right.$ drop).

The specific power $\left(\mathrm{kW} \mathrm{kg}^{-1}\right)$ was calculated by means of the formula:

$$
\mathrm{P}=\frac{\mathrm{E}}{\Delta \mathrm{t}_{\mathrm{d}}}
$$

where $\Delta t_{d}$ is the discharge time. 


\section{Acknowledgements}

This research work was supported by the Spanish MINECO (MAT2012-31651). M.S. acknowledges the award of a Ramón y Cajal contract. We thank Elena Fuertes for the design of Scheme 1.

Supporting Information Available: Thermogravimetric analysis curves, XPS spectra, same images, EELS spectrum, HRTEM images and FFT patterns, cyclic voltammograms and rate capability with the increase in sweep rate, charge/discharge voltage profiles and long-term stability at different current densities, Ragone plot in volumetric units, and enlargement of the voltage window up to $2.7 \mathrm{~V}$ along with the long-term stability at different current densities in the 0 2.7 $\mathrm{V}$ range. This material is available free of charge via the Internet at http://pubs.acs.org.

\section{References}

1. Su, D. S.; Schloegl, R. Nanostructured Carbon and Carbon Nanocomposites for Electrochemical Energy Storage Applications. ChemSusChem 2010, 3, 136-168.

2. Ghosh, A.; Lee, Y. H. Carbon-Based Electrochemical Capacitors. ChemSusChem 2012, 5, 480-499.

3. Wang, G.; Zhang, L.; Zhang, J. A Review of Electrode Materials for Electrochemical Supercapacitors. Chem. Soc. Rev. 2012, 41, 797-828.

4. Hao, L.; Li, X.; Zhi, L. Carbonaceous Electrode Materials for Supercapacitors. Adv. Mater. 2013, 25, 3899-3904.

5. Qie, L.; Chen, W.-M.; Wang, Z.-H.; Shao, Q.-G.; Li, X.; Yuan, L.-X.; Hu, X.L.; Zhang, W.-X.; Huang, Y.-H. Nitrogen-Doped Porous Carbon Nanofiber Webs as Anodes for Lithium Ion Batteries with a Superhigh Capacity and Rate Capability. Adv. Mater. 2012, 24, 2047-2050.

6. Chmiola, J.; Yushin, G.; Gogotsi, Y.; Portet, C.; Simon, P.; Taberna, P. L. Anomalous Increase in Carbon Capacitance at Pore Sizes Less Than 1 Nanometer. Science 2006, 313, 1760-1763. 
7. Portet, C.; Yushin, G.; Gogotsi, Y. Effect of Carbon Particle Size on Electrochemical Performance of EDLC. J. Electrochem. Soc. 2008, 155, A531A536.

8. Wang, D.-W.; Li, F.; Liu, M.; Lu, G. Q.; Cheng, H.-M. 3D Aperiodic Hierarchical Porous Graphitic Carbon Material for High-Rate Electrochemical Capacitive Energy Storage. Angew. Chem. Int. Ed. 2008, 47, 373-376.

9. Wang, Z.; Li, F.; Stein, A. Direct Synthesis of Shaped Carbon Nanoparticles with Ordered Cubic Mesostructure. Nano Lett. 2007, 7, 3223-3226.

10. Fang, Y.; Gu, D.; Zou, Y.; Wu, Z.; Li, F.; Che, R.; Deng, Y.; Tu, B.; Zhao, D. A Low-Concentration Hydrothermal Synthesis of Biocompatible Ordered Mesoporous Carbon Nanospheres with Tunable and Uniform Size. Angew. Chem. Int. Ed. 2010, 49, 7987-7991.

11. Su, F.; Poh, C. K.; Chen, J. S.; Xu, G.; Wang, D.; Li, Q.; Lin, J.; Lou, X. W. Nitrogen-Containing Microporous Carbon Nanospheres with Improved Capacitive Properties. Energ. Environ. Sci. 2011, 4, 717-724.

12. Chen, L.-F.; Zhang, X.-D.; Liang, H.-W.; Kong, M.; Guan, Q.-F.; Chen, P.; Wu, Z.-Y.; Yu, S.-H. Synthesis of Nitrogen-Doped Porous Carbon Nanofibers as an Efficient Electrode Material for Supercapacitors. ACS Nano 2012, 6, 7092-7102.

13. Zhang, X.-Q.; Sun, Q.; Dong, W.; Li, D.; Lu, A.-H.; Mu, J.-Q.; Li, W.-C. Synthesis of Superior Carbon Nanofibers with Large Aspect Ratio and Tunable Porosity for Electrochemical Energy Storage. J. Mater. Chem. A 2013, 1, 94499455.

14. Sun, Q.; Zhang, X.-Q.; Han, F.; Li, W.-C.; Lu, A.-H. Controlled Hydrothermal Synthesis of 1D Nanocarbons by Surfactant-Templated Assembly for Use as Anodes for Rechargeable Lithium-Ion Batteries. J. Mater. Chem. 2012, 22, 1704917054.

15. Stoller, M. D.; Park, S.; Zhu, Y.; An, J.; Ruoff, R. S. Graphene-Based Ultracapacitors. Nano Lett. 2008, 8, 3498-3502.

16. Lei, Z.; Christov, N.; Zhao, X. S. Intercalation of Mesoporous Carbon Spheres between Reduced Graphene Oxide Sheets for Preparing High-Rate Supercapacitor Electrodes. Energ. Environ. Sci. 2011, 4, 1866-1873.

17. Zhang, L. L.; Xiong, Z.; Zhao, X. S. Pillaring Chemically Exfoliated Graphene Oxide with Carbon Nanotubes for Photocatalytic Degradation of Dyes under Visible Light Irradiation. ACS Nano 2010, 4, 7030-7036.

18. Wang, G.; Sun, X.; Lu, F.; Sun, H.; Yu, M.; Jiang, W.; Liu, C.; Lian, J. Flexible Pillared Graphene-Paper Electrodes for High-Performance Electrochemical Supercapacitors. Small 2012, 8, 452-459.

19. Xu, Z.; Li, Z.; Holt, C. M. B.; Tan, X.; Wang, H.; Amirkhiz, B. S.; Stephenson, T.; Mitlin, D. Electrochemical Supercapacitor Electrodes from Sponge-Like Graphene Nanoarchitectures with Ultrahigh Power Density. J. Phys. Chem. Lett. 2012, 3, 2928-2933.

20. Liu, C.; Yu, Z.; Neff, D.; Zhamu, A.; Jang, B. Z. Graphene-Based Supercapacitor with an Ultrahigh Energy Density. Nano Lett. 2010, 10, 4863-4868.

21. Yang, X.; Zhu, J.; Qiu, L.; Li, D. Bioinspired Effective Prevention of Restacking in Multilayered Graphene Films: Towards the Next Generation of HighPerformance Supercapacitors. Adv. Mater. 2011, 23, 2833-2838. 
22. Yan, J.; Liu, J.; Fan, Z.; Wei, T.; Zhang, L. High-Performance Supercapacitor Electrodes Based on Highly Corrugated Graphene Sheets. Carbon 2012, 50, 2179-2188.

23. Liu, F.; Song, S.; Xue, D.; Zhang, H. Folded Structured Graphene Paper for High Performance Electrode Materials. Adv. Mater. 2012, 24, 1089-1094.

24. Wen, Z.; Wang, X.; Mao, S.; Bo, Z.; Kim, H.; Cui, S.; Lu, G.; Feng, X.; Chen, J. Crumpled Nitrogen-Doped Graphene Nanosheets with Ultrahigh Pore Volume for High-Performance Supercapacitor. Adv. Mater. 2012, 24, 5610-5616.

25. Song, R.; Song, H.; Zhou, J.; Chen, X.; Wu, B.; Yang, H. Y. Hierarchical Porous Carbon Nanosheets and Their Favorable High-Rate Performance in Lithium Ion Batteries. J. Mater. Chem. 2012, 22, $12369-12374$.

26. He, C.; Wu, S.; Zhao, N.; Shi, C.; Liu, E.; Li, J. Carbon-Encapsulated $\mathrm{Fe}_{3} \mathrm{O}_{4}$ Nanoparticles as a High-Rate Lithium Ion Battery Anode Material. ACS Nano 2013, 7, 4459-4469.

27. Fan, Z.; Liu, Y.; Yan, J.; Ning, G.; Wang, Q.; Wei, T.; Zhi, L.; Wei, F. Template-Directed Synthesis of Pillared-Porous Carbon Nanosheet Architectures: High-Performance Electrode Materials for Supercapacitors. Adv. Energy Mater. 2012, 2, 419-424.

28. Wang, H.; Xu, Z.; Kohandehghan, A.; Li, Z.; Cui, K.; Tan, X.; Stephenson, T. J.; King'ondu, C. K.; Holt, C. M. B.; Olsen, B. C., et al. Interconnected Carbon Nanosheets Derived from Hemp for Ultrafast Supercapacitors with High Energy. ACS Nano 2013, 7, 5131-5141.

29. Sevilla, M.; Fuertes, A. B. A General and Facile Synthesis Strategy Towards Highly Porous Carbons: Carbonization of Organic Salts. J. Mater. Chem. A 2013, 1, 13738-13741.

30. McEnaney, B. Properties of Activated Carbons. In Handbook of Porous Solids, Wiley-VCH Verlag GmbH: 2008; pp 1828-1863.

31. Al-Jishi, R.; Dresselhaus, G. Lattice-Dynamical Model for Graphite. Phys. Rev. B 1982, 26, 4514-4522.

32. Schwan, J.; Ulrich, S.; Batori, V.; Ehrhardt, H.; Silva, S. R. P. Raman Spectroscopy on Amorphous Carbon Films. J. Appl. Phys. 1996, 80, 440-447.

33. Sheng, C. Char Structure Characterised by Raman Spectroscopy and Its Correlations with Combustion Reactivity. Fuel 2007, 86, 2316-2324.

34. Sadezky, A.; Muckenhuber, H.; Grothe, H.; Niessner, R.; Pöschl, U. Raman Microspectroscopy of Soot and Related Carbonaceous Materials: Spectral Analysis and Structural Information. Carbon 2005, 43, 1731-1742.

35. Gogotsi, Y.; Simon, P. True Performance Metrics in Electrochemical Energy Storage. Science 2011, 334, 917-918.

36. Zhu, Y.; Murali, S.; Stoller, M. D.; Ganesh, K. J.; Cai, W.; Ferreira, P. J.; Pirkle, A.; Wallace, R. M.; Cychosz, K. A.; Thommes, M., et al. Carbon-Based Supercapacitors Produced by Activation of Graphene. Science 2011, 332, 1537 1541.

37. Wei, L.; Sevilla, M.; Fuertes, A. B.; Mokaya, R.; Yushin, G. Hydrothermal Carbonization of Abundant Renewable Natural Organic Chemicals for HighPerformance Supercapacitor Electrodes. Adv. Energy Mater. 2011, 1, 356-361. 
38. Yun, Y. S.; Cho, S. Y.; Shim, J.; Kim, B. H.; Chang, S.-J.; Baek, S. J.; Huh, Y. S.; Tak, Y.; Park, Y. W.; Park, S., et al. Microporous Carbon Nanoplates from Regenerated Silk Proteins for Supercapacitors. Adv. Mater. 2013, 25, 1993-1998.

39. Qie, L.; Chen, W.; Xu, H.; Xiong, X.; Jiang, Y.; Zou, F.; Hu, X.; Xin, Y.; Zhang, Z.; Huang, Y. Synthesis of Functionalized 3D Hierarchical Porous Carbon for High-Performance Supercapacitors. Energ. Environ. Sci. 2013, 6, 2497-2504.

40. Liang, Y.; Liang, F.; Zhong, H.; Li, Z.; Fu, R.; Wu, D. An Advanced Carbonaceous Porous Network for High-Performance Organic Electrolyte Supercapacitors. J. Mater. Chem. A 2013, 1, 7000-7005.

41. Taberna, P. L.; Simon, P.; Fauvarque, J. F. Electrochemical Characteristics and Impedance Spectroscopy Studies of Carbon-Carbon Supercapacitors. J. Electrochem. Soc. 2003, 150, A292-A300.

42. Portet, C.; Taberna, P. L.; Simon, P.; Flahaut, E.; Laberty-Robert, C. High Power Density Electrodes for Carbon Supercapacitor Applications. Electrochim. Acta 2005, 50, 4174-4181.

43. Liu, N.; Shen, J.; Liu, D. Activated High Specific Surface Area Carbon Aerogels for Edlcs. Micropor. Mesopor. Mater. 2013, 167, 176-181.

44. Li, X.; Han, C.; Chen, X.; Shi, C. Preparation and Performance of Straw Based Activated Carbon for Supercapacitor in Non-Aqueous Electrolytes. Micropor. Mesopor. Mater. 2010, 131, 303-309.

45. Lota, G.; Centeno, T. A.; Frackowiak, E.; Stoeckli, F. Improvement of the Structural and Chemical Properties of a Commercial Activated Carbon for Its Application in Electrochemical Capacitors. Electrochim. Acta 2008, 53, 2210-2216.

46. Korenblit, Y.; Rose, M.; Kockrick, E.; Borchardt, L.; Kvit, A.; Kaskel, S.; Yushin, G. High-Rate Electrochemical Capacitors Based on Ordered Mesoporous Silicon Carbide-Derived Carbon. ACS Nano 2010, 4, 1337-1344.

47. Xu, H.; Gao, Q.; Guo, H.; Wang, H. Hierarchical Porous Carbon Obtained Using the Template of Naoh-Treated Zeolite B and Its High Performance as Supercapacitor. Micropor. Mesopor. Mater. 2010, 133, 106-114.

48. Liu, W.-w.; Yan, X.-b.; Lang, J.-w.; Pu, J.-b.; Xue, Q.-j. Supercapacitors Based on Graphene Nanosheets Using Different Non-Aqueous Electrolytes. New J. Chem. 2013, 37, 2186-2195.

49. Hou, L.; Lian, L.; Li, D.; Pang, G.; Li, J.; Zhang, X.; Xiong, S.; Yuan, C. Mesoporous N-Containing Carbon Nanosheets Towards High-Performance Electrochemical Capacitors. Carbon 2013, 64, 141-149.

50. Puthusseri, D.; Aravindan, V.; Madhavi, S.; Ogale, S. 3D Micro-Porous Conducting Carbon Beehive by Single Step Polymer Carbonization for High Performance Supercapacitors: The Magic of in situ Porogen Formation. Energ. Environ. Sci. 2014, 7, 728-735.

51. Li, Y.; Li, Z.; Shen, P. K. Simultaneous Formation of Ultrahigh Surface Area and Three-Dimensional Hierarchical Porous Graphene-Like Networks for Fast and Highly Stable Supercapacitors. Adv. Mater. 2013, 25, 2474-2480.

52. Qian, W.; Sun, F.; Xu, Y.; Qiu, L.; Liu, C.; Wang, S.; Yan, F. Human HairDerived Carbon Flakes for Electrochemical Supercapacitors. Energ. Environ. Sci. 2014, 7, 379-386. 
53. Sun, L.; Tian, C.; Li, M.; Meng, X.; Wang, L.; Wang, R.; Yin, J.; Fu, H. From Coconut Shell to Porous Graphene-Like Nanosheets for High-Power Supercapacitors. J. Mater. Chem. A 2013, 1, 6462-6470.

54. Iso 9277:2010. Determination of the Specific Surface Area of Solids by Gas Adsorption - Bet Method. Second Edition of Iso 9277, Iso; Geneva, 2012.

55. Dubinin, M. M. Fundamentals of the Theory of Adsorption in Micropores of Carbon Adsorbents: Characteristics of Their Adsorption Properties and Microporous Structures. Carbon 1989, 27, 457-467.

56. Stoeckli, F.; Ballerini, L. Evolution of Microporosity During Activation of Carbon. Fuel 1991, 70, 557-559.

57. Neimark, A. V.; Lin, Y.; Ravikovitch, P. I.; Thommes, M. Quenched Solid Density Functional Theory and Pore Size Analysis of Micro-Mesoporous Carbons. Carbon 2009, 47, 1617-1628.

58. Ravikovitch, P. I.; Neimark, A. V. Density Functional Theory Model of Adsorption on Amorphous and Microporous Silica Materials. Langmuir 2006, 22, 11171-11179. 


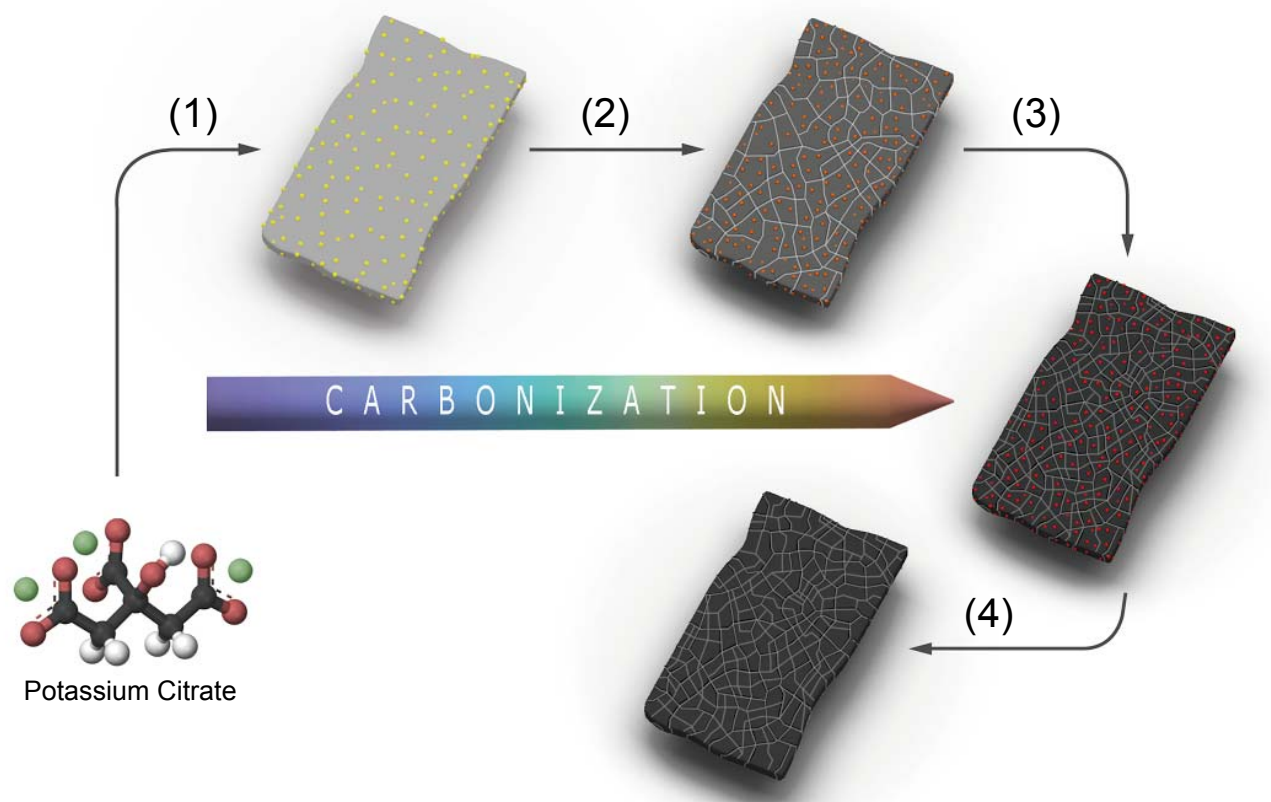

Scheme 1. Synthesis scheme for the preparation of porous carbon nanosheets from potassium citrate. (1) Pyrolysis of the organic moiety and formation of $\mathrm{K}_{2} \mathrm{CO}_{3}$; (2) decomposition of $\mathrm{K}_{2} \mathrm{CO}_{3}$ with formation of $\mathrm{K}_{2} \mathrm{O}$ (gasification and chemical activation reactions); (3) reduction of $\mathrm{K}_{2} \mathrm{O}$ with formation of metallic $\mathrm{K}$ (chemical activation and $\mathrm{K}$ intercalation processes); (4) removal of potassium inorganic compounds (washing). 
Table 1. Textural properties of porous carbon nanosheets.

\begin{tabular}{|l|l|l|l|l|l|}
\hline Sample Code & $\mathrm{T},{ }^{\circ} \mathrm{C}^{\mathrm{a}}$ & $\mathrm{S}_{\text {BET }}\left(\mathrm{m}^{2} \cdot \mathrm{g}^{-1}\right)$ & $\mathrm{V}_{\mathrm{p}}\left(\mathrm{cm}^{3} \cdot \mathrm{g}^{-1}\right)^{\mathrm{b}}$ & $\mathrm{V}_{\text {micro }}\left(\mathrm{cm}^{3} \cdot \mathrm{g}^{-1}\right)^{\mathrm{c}}$ & $\mathrm{V}_{\text {meso }}\left(\mathrm{cm}^{3} \cdot \mathrm{g}^{-1}\right)^{\mathrm{d}}$ \\
\hline CK-750 & 750 & 1360 & 0.59 & $0.54(0.8 \mathrm{~nm})$ & 0.05 \\
\hline CK-800 & 800 & 1940 & 0.96 & $0.77(1.4 \mathrm{~nm})$ & 0.19 \\
\hline CK-850 & 850 & 2220 & 1.11 & $0.84(1.6 \mathrm{~nm})$ & 0.27 \\
\hline CK-900 & 900 & 2160 & 1.30 & $0.82(1.9 \mathrm{~nm})$ & 0.48 \\
\hline
\end{tabular}

${ }^{a}$ Carbonization temperature; ${ }^{b}$ Pore volume at $\mathrm{p} / \mathrm{p}_{\mathrm{o}} \sim 0.95 .{ }^{\mathrm{c}}$ Micropore volume was determined by applying the Dubinin-Radushkevich (D-R) method to $\mathrm{N}_{2}$ adsorption branch; the mean micropore size, deduced by the D-R method, is indicated in brackets. ${ }^{\mathrm{d}}$ Mesopore volume obtained by the difference between pore volume $\left(\mathrm{V}_{\mathrm{p}}\right)$ and micropore volume $\left(\mathrm{V}_{\text {micro }}\right)$. 

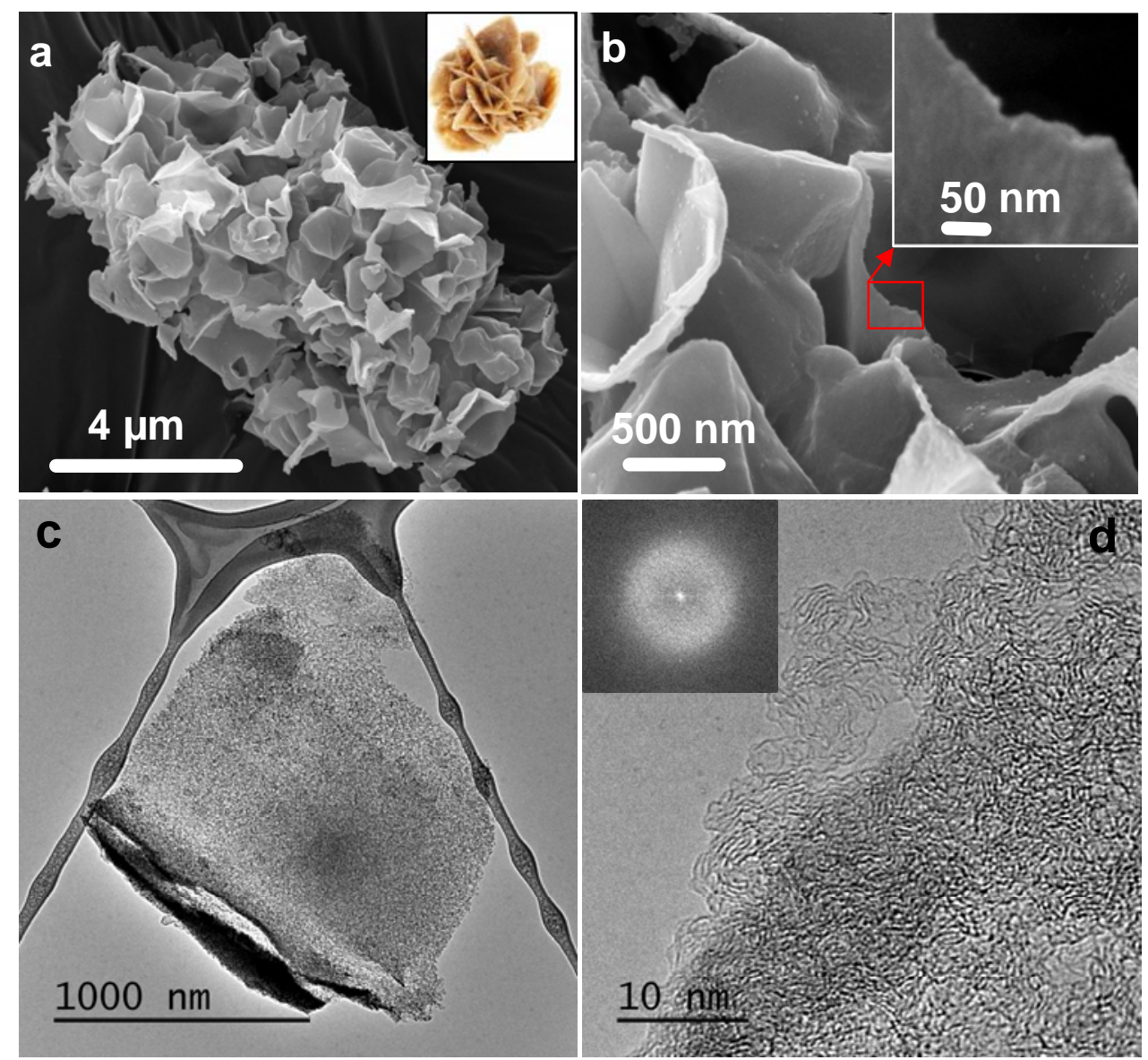

Figure 1. (a, b) SEM images of interconnected carbon nanosheets of sample CK850. Inset in (a) shows a photograph of a desert rose and inset in (b) displays a high-magnification detail revealing the thinness of the carbon nanosheets. (c) TEM image of a CK-900 nanosheet highlighting its porous structure. (d) HRTEM image of the edge of a carbon nanosheet of CK-850. Inset in (d) shows the FFT pattern revealing the amorphous structure of the carbon nanosheets of CK-850. 

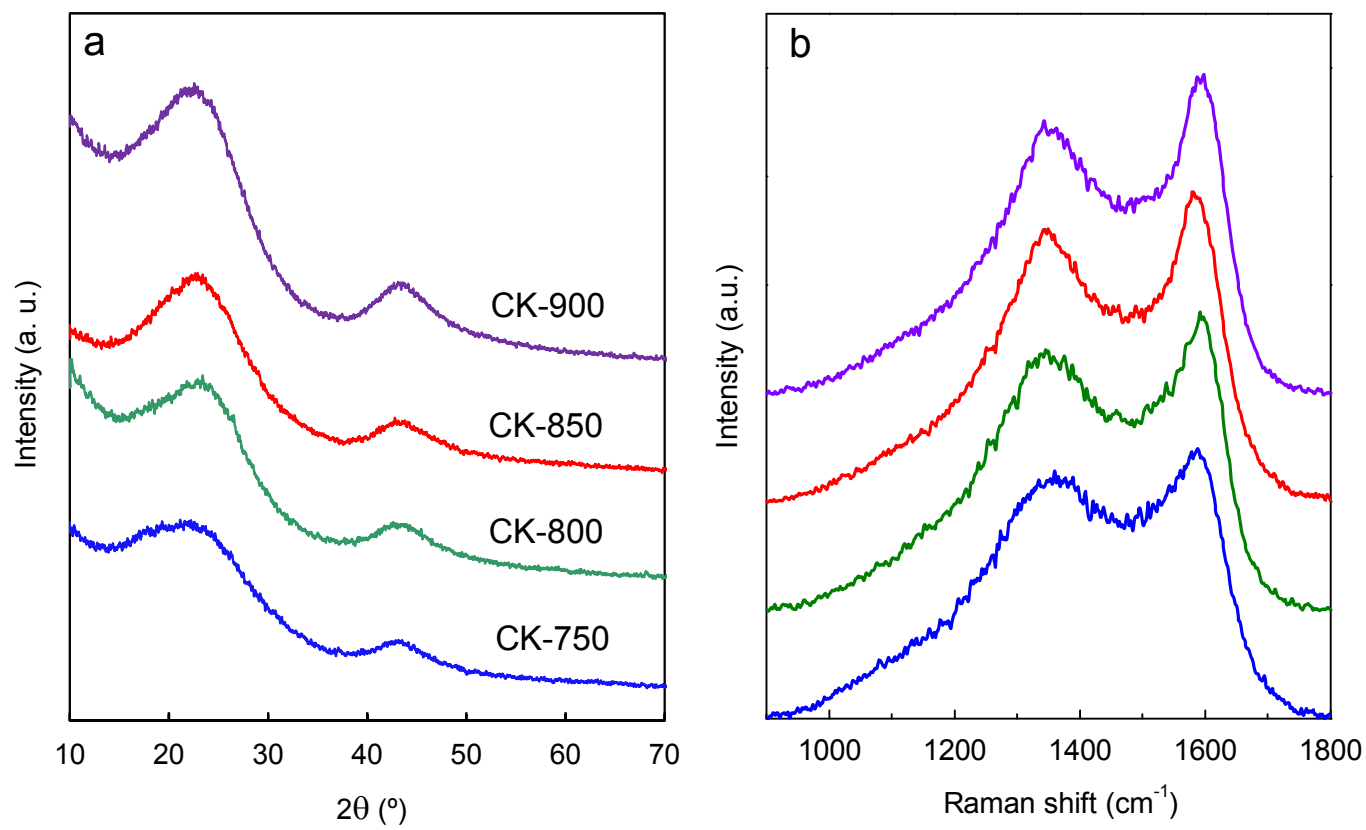

Figure 2. (a) XRD patterns and (b) Raman spectra of the carbon nanosheets. 

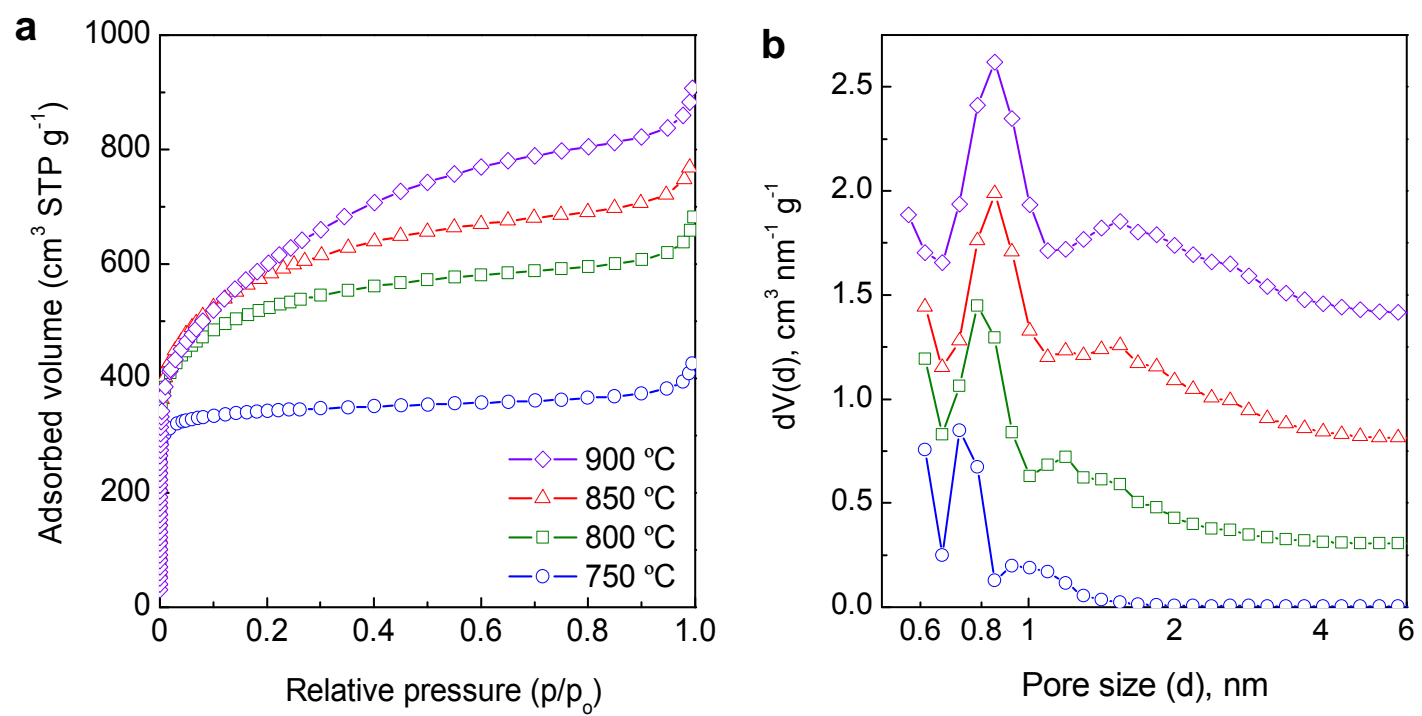

Figure 3. (a) Nitrogen sorption isotherms and (b) pore size distributions deduced by means of the QSDFT method for the PCNS prepared at different carbonization temperatures in the $750-900^{\circ} \mathrm{C}$ range. 
a

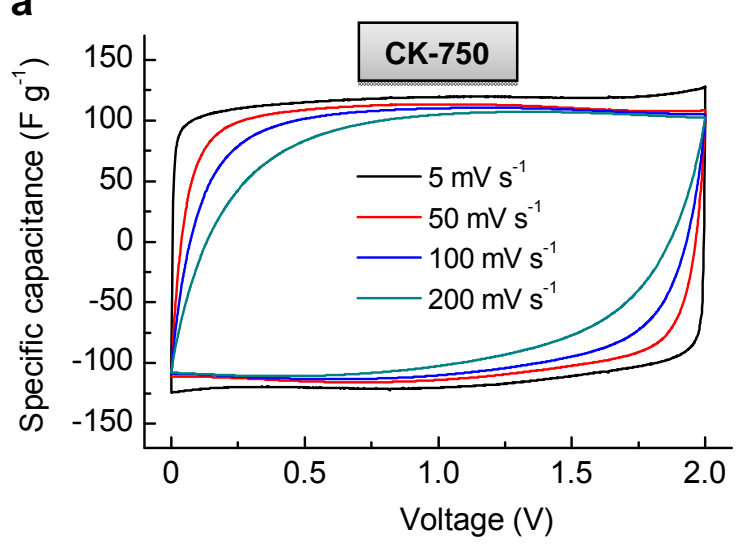

C

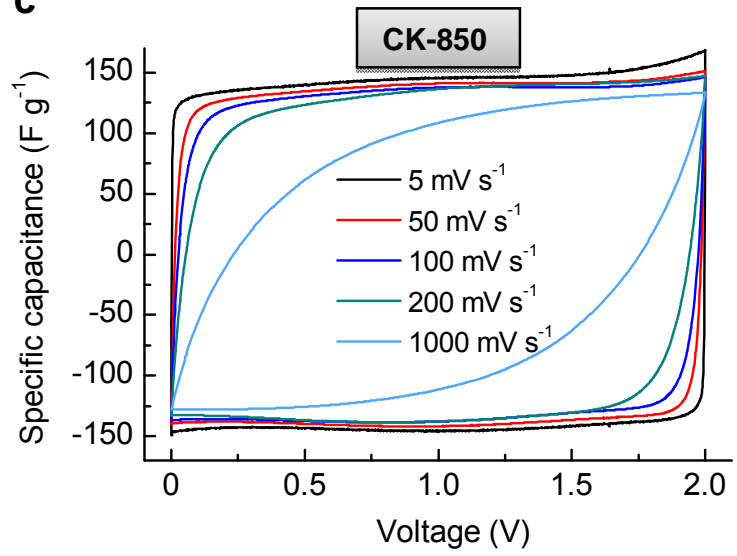

b

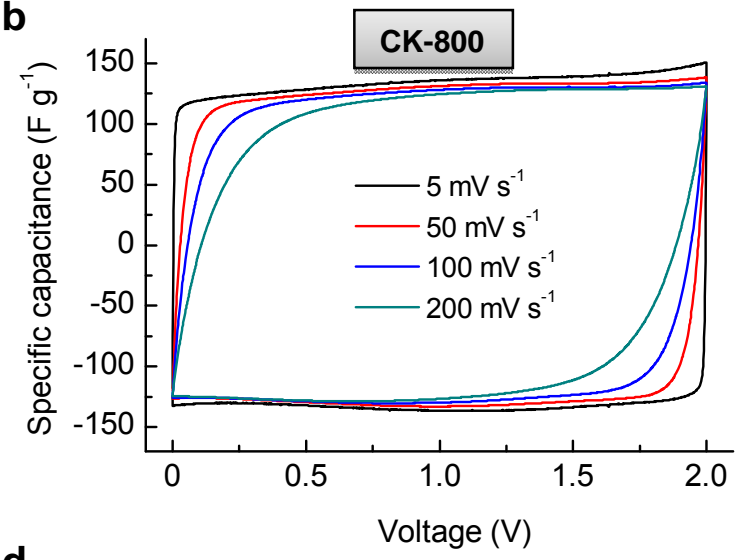

d

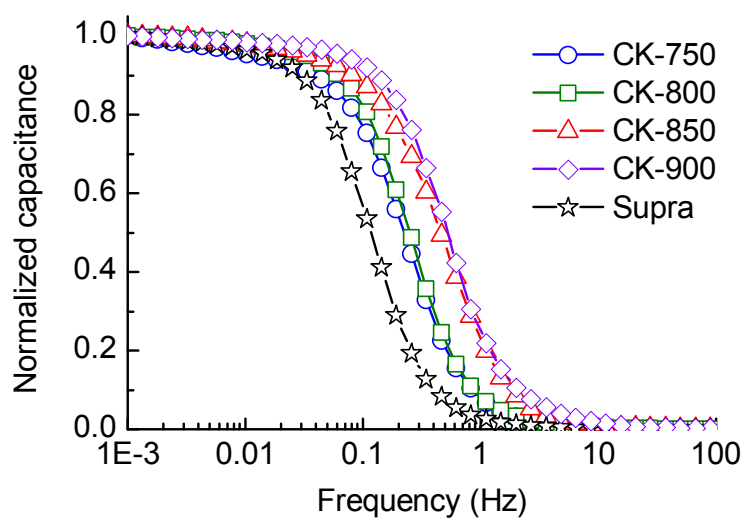

Figure 4. $a, b$ and c) Cyclic voltammograms at different scan rates in $1 \mathrm{M}$ $\mathrm{TEABF}_{4} / \mathrm{AN}$ for the different PCNs, and d) frequency response of the PCNS and commercial activated carbon Supra. 

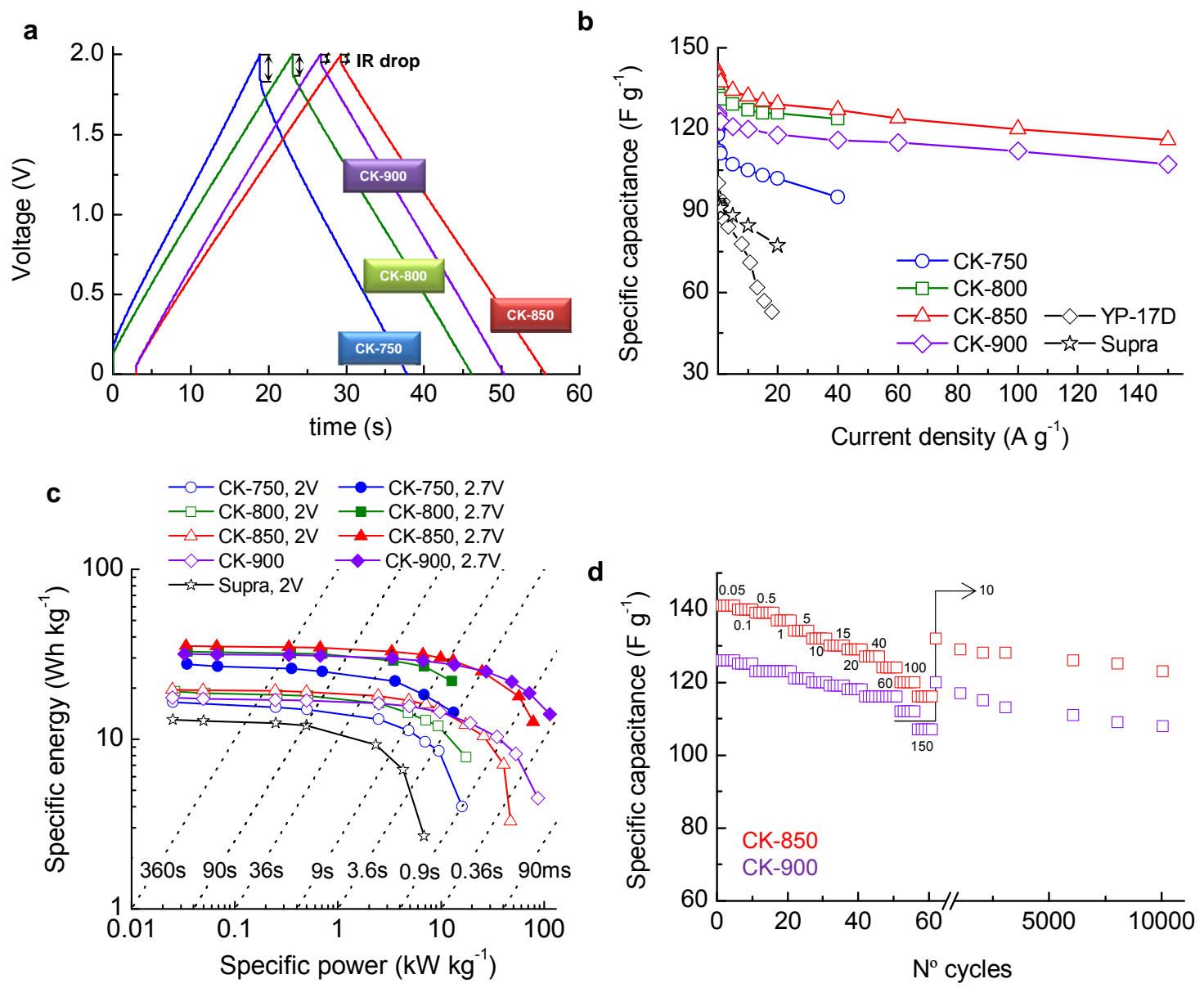

Figure 5. a) Charge/discharge voltage profile at $5 \mathrm{~A} \mathrm{~g}^{-1}$ (the voltage profiles of $\mathrm{CK}$ 850 and CK-900 have been displaced by 3 s for clarity), b) charge/discharge rate performance, and c) Ragone plot of the PCNS samples and the activated carbon Supra in $1 \mathrm{M} \mathrm{TEABF}_{4} / \mathrm{AN}$, and d) cycling stability at different current densities (in $\mathrm{A}$ $\mathrm{g}^{-1}$ ) in the $0-2 \mathrm{~V}$ range for CK-850 and CK-900. 


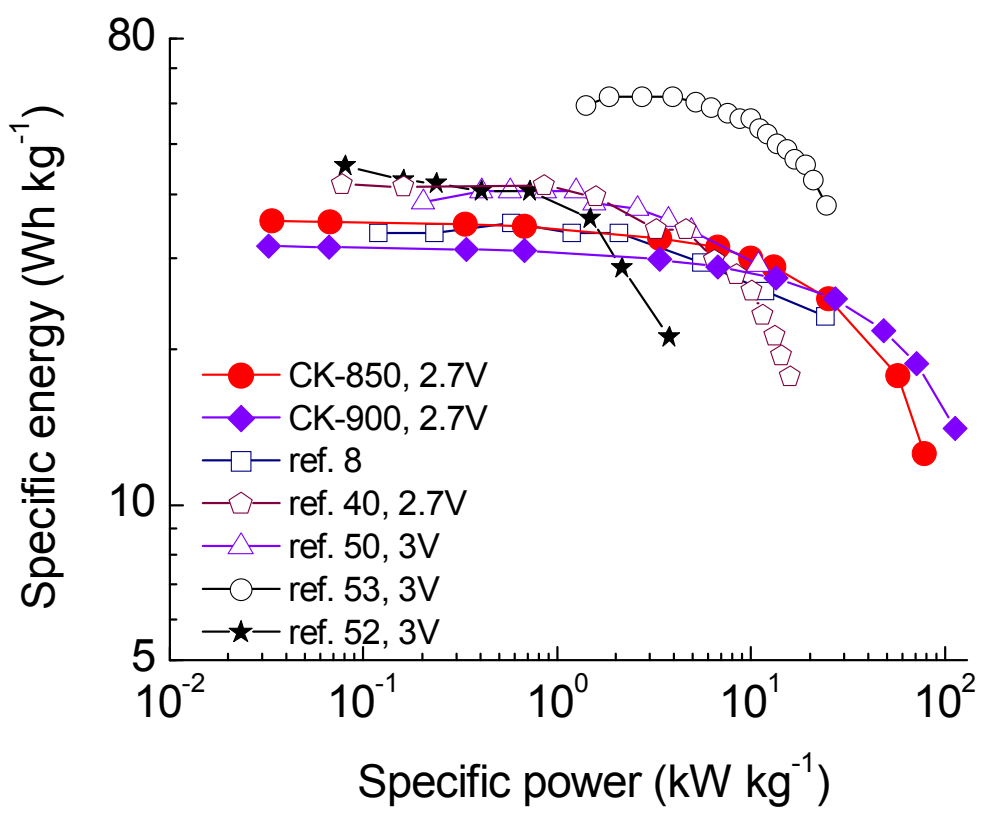

Figure 6. Ragone plot of advanced porous carbon materials that can be found in the literature with outstanding behavior as supercapacitor electrodes in organic electrolyte. 